This article is part of the Special Issue "To Be Both (and More): Immigration and Identity Multiplicity; Special," Fenella Fleischmann, Shaun Wiley, Maykel Verkuyten and Kay Deaux (Special Issue Editors). For a full listing of Special Issue papers, see: http://onlinelibrary.wiley.com/doi/ 10.1111/josi.2019.75.issue-2/issuetoc.

\title{
The Up- and Downside of Dual Identity: Stereotype Threat and Minority Performance
}

\author{
Gülseli Baysu* \\ Queen's University Belfast
}

\section{Karen Phalet}

Katholieke Universiteit Leuven

Social identity and acculturation research mostly documents benefits of dual identity for immigrant minorities' adaptation. Drawing on stereotype threat research, we argue that dual identity can be (1) beneficial in low-threat contexts and (2) costly in high-threat contexts. Two field experiments in schools induced stereotype threat by randomly assigning minority students (Study 1: $N=174$, Study 2: $N=735$ ) to stereotype threat (making ethnicity salient) versus control conditions before taking a test. We assessed dual identity as dual commitments to (combined) minority and majority cultures. In support of the predicted benefits of dual identity in low-threat contexts, dual identifiers outperformed and had higher self-esteem than did otherwise-identified students in the control condition, while the advantage of dual identity disappeared in the threat condition (Study 1). In support of the predicted costs of a dual identity in high-threat contexts, dual identifiers reported more anxiety (Study 1) and performed worse (Study 2) in the threat condition compared to the control condition. These experimental findings suggest that dual identities may either help or hinder minority performance depending on stereotype threat in academic contexts.

With continuing immigration into Western countries, the integration and success of immigrant minorities has become a major public concern. International

\footnotetext{
* Correspondence concerning this article should be addressed to Dr. Gülseli Baysu, Queen's University Belfast, School of Psychology, University Road, Belfast, BT7 1NN, Northern Ireland, UK [e-mail: g.baysu@qub.ac.uk or gulseli.baysu@ gmail.com].

This research is supported by grants from the Research Foundation-Flanders (Fonds Wetenschappelijk Onderzoek-FWO G.0747.13) and University of Leuven Research Council (Interdisciplinaire Onderzoeksprogramma-IDO10.005).

This special issue is based on a EASP-SPSSI Joint Meeting, September 15-17, 2017, near Utrecht, the Netherlands, organized by the editors.
} 
studies find a persistent educational disadvantage of the children of immigrant workers (OECD, 2015). Even controlling for parental and individual background, Turkish and Moroccan minority students in Europe lag behind their majority peers with long-term consequences for unequal chances later in life (Baysu, de Valk, \& Alanya, 2018; Heath \& Brinbaum, 2014). Not only are these students disadvantaged as children of immigrant-workers, they are also targets of discrimination and negative stereotyping against Muslims in Europe (Phalet, Fleischmann, \& Hillekens, 2018). Against this background, and given their double membership in the minority community and the wider society, immigrant minorities (particularly the second- and later generations) have to negotiate their commitments to minority and majority cultures. Accordingly, this article examines the academic (under)performance of Turkish- and Moroccan-minority students in Belgian secondary schools as a function of their exposure to negative stereotyping and their commitments to both cultures.

Both social identity and acculturation research documents an adaptive advantage of dual identity (Berry, Phinney, Sam \& Vedder, 2006; Makarova \& Birman, 2015; Nguyen \& Benet-Martínez, 2013). While dual identities are associated with several social and cognitive benefits, recent findings also reveal psychological costs, particularly when the environment does not support dual identities (Brown et al., 2013; Brown \& Zagefka, 2011; Phalet \& Baysu, 2019). Not much empirical research, however, has addressed the question of which factors can make dual identities beneficial or harmful in a performance context (Baysu, Phalet, \& Brown, 2011).

Our explanatory focus is on minority experiences of "stereotype threat" (ST) (Steele, Spencer, \& Aronson, 2002). As minority youth derive self-worth from their minority-group membership, they will experience ST whenever they face negative stereotypes about their group's competence. Whereas the costs of ST for the academic performance of immigrant youth are well established (Appel, Weber, \& Kronberger, 2015; Steele et al., 2002), this research assumes that minorities are identified with the devalued minority culture. It does not usually assess their identification with both minority and majority cultures. Bridging research on ST with a social identity approach of dual identities, the present research aims to explain the academic performance of minority students from the interaction of their dual identities with ST in school. A better understanding of this interaction has important applied implications for the creation of inclusive learning environments in culturally diverse schools.

\section{Benefits and Costs of Dual Identity}

Bridging a social identity approach of dual identities (Verkuyten, Wiley, Deaux, \& Fleischmann, 2019) with acculturation research among immigrant minority youth (Berry et al., 2006; Brown \& Zagefka, 2011), we define dual 
identifiers as minority persons who are committed to both the minority and majority cultures. Dual identities denote their self-investment in two cultural groups of which they feel part and in which they are behaviorally involved (Ashmore, Deaux, \& Mclaughlin-Volpe, 2004). From a social identity performance perspective (Klein, Spears, \& Reicher, 2007), dual identities require "identity performance" in line with both minority and majority cultural norms and practices to be psychologically sustainable. Measures of acculturation attitudes and behaviors used to assess "integration" capture the endorsement and enactment of cultural group norms that make up dual identity performance. These aspects of dual identities are related but distinct from other psychological aspects of group identities, such as importance or embeddedness (Ashmore et al., 2004; Verkuyten et al., 2019).

To be psychologically viable and secure, our social identities require social validation and valuation in interactions with others as "audiences" of identity performance (Klein et al., 2007). Relevant audiences of identity performance for minorities are their fellow minority group members but others in society can be relevant as well (Phalet, Baysu, \& Verkuyten, 2010). Particularly for dual identifiers, both minority and majority groups are relevant audiences of identity performance. Thus, dual identifiers will benefit in the presence of double valuation from minority and majority groups. Conversely, they are also at double risk of being denied their identity from either side (Badea, Jetten, Iyer, \& Er-Rafiy, 2011; Cardenas, 2019; Wiley, Fleischmann, Deaux, \& Verkuyten, 2019).

Acculturation research has documented the psychological benefits of dual identities for minorities (Makarova \& Birman, 2015; Nguyen \& Benet-Martínez, 2013; Verkuyten et al., 2019 for reviews). Not only do they combine social-support networks in both minority and majority groups (Mok, Morris, Benet-Martínez, \& Karakitapoglu-Aygun, 2007), they are attuned to both minority and majority cultural norms, and hence better able to navigate cross-group relationships (Celeste, Meeussen, Verschueren, \& Phalet, 2016). Dual identities have also been associated with distinctive cognitive gains, such as enhanced perspective taking and integrative complexity, which may bring a competitive advantage in performance situations (Crisp \& Turner, 2011).

Dual identities or "being both" can also be psychologically demanding for minorities, however, if they have to maintain different social networks and negotiate different norms and expectations from minority and majority cultures (Phalet \& Baysu, 2019). Inhabiting two social and cultural worlds implies that both minority and majority group members are relevant audiences of their identity performance who might deny their dual identity claims (Verkuyten et al., 2019). Accordingly, minority adolescents who preferred a dual identity were most at risk of experiencing social rejection in school, when their minority peers stressed minority culture maintenance and when their majority peers valued mainstream culture adoption (Celeste et al., 2016). Acculturation research generally supports 
the idea that majority members are relevant audiences for minority members with dual identities, because the adaptive value of dual identities (or integration) also depends on whether the majority group accepts minority identities and cultures (Nguyen \& Benet-Martínez, 2013; Phalet \& Baysu, 2019). In their meta-analysis, for instance, Nguyen and Benet-Martínez (2013) found that an alleged adaptive advantage of dual identities was less clear-cut in European countries, where the majority population commonly rejects dual identity claims by minorities (Verkuyten \& Martinoviç, 2012).

In sum, dual identifiers strive to sustain good relations with majority members and to be accepted as minority members. Living in two social and cultural worlds comes with psychological benefits, when dual identifiers feel valued by both minority and majority groups. However, being responsive to double valuation also makes them vulnerable to identity devaluation in their dealings with members of either or both cultural groups. We conceive of ST as signaling devaluation. Not much empirical research has addressed ST as a critical condition that makes for performance benefits and/or costs of dual identities.

\section{Stereotype Threat and Minority Performance}

"Stereotype threat" experiments have demonstrated that situationally induced negative stereotypes of low academic ability have debilitating effects on the performance of stereotyped group members (Steele et al., 2002). From a social identity perspective, ST is a situational type of identity threat. Accordingly, minority youth experience identity threat whenever the environment signals (explicitly or implicitly) that their minority identity is not valued, such as when they encounter discriminatory treatment or negative stereotyping (Branscombe, Ellemers, Spears, \& Doosje, 1999; Derks, van Laar, \& Ellemers, 2007).

In line with ST (Steele et al., 2002) and social identity theories (Ellemers, Spears, \& Doosje, 2002), vulnerability to identity threat depends on different levels of commitment to the devalued group(s). The more we are committed to a devalued group, the more we will feel threatened in our social identity, whenever this in-group becomes the target of negative stereotyping (Branscombe et al., 1999; Derks et al., 2007). For instance, more gender-identified women or more race-identified African-Americans were more vulnerable to ST (Ployhart, Ziegert, \& McFarland, 2003; Schmader, 2002). However, a recent meta-analysis of ST studies with immigrant populations (Appel et al., 2015) reported inconsistent findings of negative, zero, or positive moderation of ST effects by ethnic minority identification, suggesting that minority identification can either buffer or hamper minority performance under threat.

One reason for these mixed findings could be the failure of earlier ST research to acknowledge that most ethnic minority youth combine both minority and majority cultures and identities (Berry et al., 2006). As Shapiro and colleagues suggest 
(Shapiro \& Neuberg, 2007; Shapiro, Williams, \& Hambarchyan, 2013), a person must acknowledge both the target of threat (the ethnic minority group) and the source of threat (the majority group) as self-relevant in the situation for ST to occur. These conditions typically apply to dual identifiers. Accordingly, our research looks beyond the ethnic identities of minority youth and articulates how ST interacts with dual identities.

\section{The Interaction of Stereotype Threat and Dual Identity}

Our research addresses the hitherto under-researched role of the dual identities of immigrant minorities in their psychological responses to ST. As dual identities require social validation and valuation from both minority and majority cultural groups (Klein et al., 2007; Phalet et al., 2010), dual identifiers can get caught in the crossfire between both groups in the presence of ST (Shapiro \& Neuberg, 2007; Shapiro, Williams, \& Hambarchyan, 2013). Accordingly, we hypothesized that dual identifiers would be most vulnerable to ST in the school context because they are simultaneously self-invested in the majority group (as the source of threat) and in the minority group (as the target of threat).

In support of this reasoning, Derks and colleagues (2007) found that dual identifiers showed less motivated performance when only majority characteristics were valued than when both minority and majority characteristics were valued (Derks et al., 2007). Likewise, Deaux et al. (2007) showed that second-generation Afro-Caribbeans in the United States performed worse in an ST experiment, but not first-generation Afro-Caribbeans. They attributed this finding to generational differences in ethnic-racial identification, as second-generation Afro-Caribbeans would be more likely to identify as (hyphenated) African-Americans rather than (ethnic) West-Indians. Because African-American identity is negatively stereotyped in the United States, the second-generation would be more vulnerable to racial stereotyping. If a hyphenated African-American identity can be likened to a dual identity in immigrant minorities, these findings suggest a possible downside of dual identities in threatening contexts.

Two separate studies with Turkish and Moroccan minorities in Belgium prepared the ground for the present research. A first experimental study showed the main effects of experimentally induced ST on test performance of Turkish and Moroccan minorities (using the same data set-Children of Immigrants Longitudinal Study CILS Belgium-as Study 2; Baysu, Celeste, Brown, Verschueren, \& Phalet, 2016). This study also showed the distinctive effects of self-reported discrimination experiences in school on minority academic performance. The present research adds to these earlier findings by testing the interaction of the ST condition with the dual identity of minority students.

Moreover, an earlier study using retrospective data from The Integration of the European Second generation (TIES) surveys in Belgium (Baysu et al., 2011) 
provides initial correlational evidence of the contingent benefits and costs of dual identities under low versus high perceived discrimination in school among Turkish minority youth. Dual identifiers, who were committed to both Turkish minority and Belgian majority identities, were less successful when discrimination was high. Conversely, when discrimination was low, they outperformed their peers with either "separated" (mainly Turkish) or "assimilated" (mainly Belgian) identifications. While discrimination is a chronic source of identity threat, ST is more situational. The present research thus adds to these findings by experimentally testing ST effects on minority performance. It replicates the performance costs or benefits of dual identities with objective test performance and across different measures of dual identity.

\section{The Present Research}

To test the benefits or costs of a dual identity in a performance situation, two field experiments manipulated ST in ethnically diverse secondary schools in Belgium. We used a classic ST manipulation to make a negatively stereotyped identity salient in a performance situation (Steele et al., 2002). Study 1 used a direct measure of dual identity (Benet-Martínez \& Haritatos, 2005), asking Turkishand Moroccan-Belgian minority students to what extent they felt part of a combined culture. Study 2 assessed dual identity indirectly as the product of separate importance ratings for majority culture adoption and minority culture maintenance (Berry et al., 2006). These measures reflect the self-investment of minority youth in combined minority and majority cultures and identities (Ashmore et al., 2004), as distinct from other psychological aspects of belonging (Verkuyten et al., 2019).

In line with our hypothesis about the vulnerability of dual identifiers to ST, and across both studies, we predicted (1) that the benefits of a dual identity would be restricted to low-threat contexts so that dual identifiers would do better than others in the control (but not in the threat) condition; (2) that a dual identity would be costly in high-threat contexts so that dual identifiers would do worse in the threat than in the control condition; and (3) that a dual identity can also be more costly than other orientations in high-threat contexts so that dual identifiers would do worse than others in the threat (but not in the control) condition.

Both studies sampled Turkish and Moroccan minorities because we were interested in the consequences of dual identities for most stigmatized Muslim minority youth. However, the two field experiments in schools included Belgian majority and other less stigmatized minority students, for example, from other EU countries, as well. Theoretically, our ST manipulations should not affect their performance. Neither the experimental manipulation (for both groups) nor the interaction with dual identity (for the less stigmatized minorities) was significant. More information is available in the Supplementary Online Material at: https://mfr.osf.io/render?url=https $\% 3 \mathrm{~A} \% 2 \mathrm{~F} \% 2 \mathrm{Fosf.io} \% 2 \mathrm{Furbkq} \% 2 \mathrm{Fdownload}$. 
Study 1

Study 1 aimed to examine the role of a dual identity in minority performance under ST among high-achieving and academically oriented Turkish and Moroccan Belgian minority students. We selected this sample for our first study to ensure sufficient academic identification, and hence their susceptibility to ST in the academic domain (Steele et al., 2002). We thus selected academic and professional types of secondary schools only. In the Belgian educational system, academic or professional secondary schools prepare students for higher education, whereas vocational schools lead to the labor market (Baysu et al., 2018).

Students were assigned to either experimental or control conditions in a field experiment using a typical manipulation of ST: having students fill out questions about ethnicity immediately preceding the test to make their ethnicity situationally salient (Steele et al., 2002). This minimal manipulation resulted in performance decrements for women and minorities in several experimental studies (Ambady, Shih, Kim, \& Pittinsky, 2001; McGlone \& Aronson, 2006). In the control condition, students answered questions unrelated to their ethnicity preceding the test.

We measured objective performance on a verbal test, as verbal ability is the most negatively stereotyped domain for Turkish and Moroccan minorities in Europe (Verkuyten \& Kinket, 1999). We also measured self-reported anxiety during the test because ST is seen to reflect increased anxiety about confirming a negative group stereotype (Spencer, Steele, \& Quinn, 1999; Steele et al., 2002). As ST can complicate the development of a strong academic self-concept (Aronson \& Inzlicht, 2004), we also measured students' momentary perceptions of competence, that is, their performance state self-esteem (Heatherton \& Polivy, 1991). Study 1 used the "overlap" dimension of the "bicultural identity integration" scale as a direct measure of dual identity (Benet-Martínez \& Haritatos, 2005), ${ }^{1}$ distinguishing dual identifiers who were feeling part of a combined culture from otherwise-identified students (i.e., who were not feeling part of a combined culture).

\footnotetext{
${ }^{1}$ Benet-Martínez and Haritatos (2005) distinguish between two dimensions in the Bicultural Identity Integration scale: distance (vs. overlap) and conflict (vs. harmony). They suggest that only the distance (vs. overlap) dimension with four items predicts performance-related aspects of acculturation. Factor analysis and inspection of item correlations suggested that "distance" items ("I am simply a member of my cultural group who lives in Belgium" and "I keep my group's culture and Belgian culture separate") and "overlap" items (the two items reported in Study 2) formed orthogonal factors in our sample (interfactor correlation $r=.058, p=.513$ ). Since only "overlap" refers directly to participants' commitment to bicultural integration, we created a composite measure with the two overlap items.
} 
Method

Participants. Participants were students of 4th-6th grades in academic or professional secondary schools in Belgium. Minority students $(N=174$, boys $56 \%$ ) were local-born of Turkish or Moroccan parentage and self-identified as Turkish or Moroccan. Their age ranged from 15 to 22 years $(M=18 ; S D=1.60)$.

Procedure and Design. Students were given a test booklet upon arrival in class. Instructions ensured that their responses would be anonymous. To deemphasize the evaluative nature of the tests in both conditions as in the original experiments (Steele \& Aronson, 1995), the researcher explained that this was a pilot study to develop new test instruments; and it was important that every student filled in every question as best as they could. Minority students were randomly assigned to one of the two conditions in which they had to fill out a short questionnaire (Ambady et al., 2001). In the ST condition (51\%), they answered a few questions on their ethnicity (e.g., which language they spoke at home) and a question reminding them of negative stereotypes ("whether Belgian students did better in school than students from other cultural backgrounds?"). In the control condition (49\%), students answered questions unrelated to their ethnic background (e.g., "whether they liked outdoor activities"). After the manipulation, they took a verbal ability test (a multiple-choice test to be completed in 10 minutes). In a separate session, they completed the post-test measures of test anxiety and self-esteem and the dual identity measures.

\section{Measures}

Verbal ability test performance was measured by the Verbal Analogies subtest of the Dutch Groninger Intelligence Test (Luteijn \& van der Ploeg, 1983). A subset of 10 most difficult items was used to sum up the correct answers $(M=$ 2.10; $S D=1.33$, range: $0-5){ }^{2}$

Performance state self-esteem was assessed with seven items from the performance state self-esteem scale (e.g., "I feel as smart as others.") (Heatherton \& Polivy, 1991). Responses were on 7-point scales $(1=$ not at all, $7=$ very much, $M=5.06 ; S D=1.01, \alpha=.68$ ).

Test anxiety during the test was measured with two reverse-coded anxietyrelated items (calm, relaxed) on 7-point scales, from (1) not at all to (7) very much,

\footnotetext{
${ }^{2}$ Items with correct response rates under $45 \%$ across majority and minority students were defined as "difficult" and hence included in the measure. The 10 excluded items turned out to be very easy for our high-achieving sample (\% correct for the excluded items was 87\%). Stereotype threat effects are expected on difficult tasks and tested with selected difficult items (e.g., Steele \& Aronson, 1995, selected difficult items of the GRE verbal test).
} 
$M=2.85, S D=1.49$, Spearman-Brown reliability (used for two-item scales): .46 (Spencer et al., 1999). Analysis of test anxiety excluded one case as a multivariate outlier (standardized residual $=3$ ).

Dual identity was measured directly by two items from the bicultural identity integration scale (Benet-Martínez \& Haritatos, 2005): "I feel part of a combined culture" and "I feel both a member of my cultural group and Belgian" (SpearmanBrown reliability $=.86)$. Answers were given on 7-point scales $(0=$ not at all, $7=$ very strongly, $M=4.91, S D=1.70)$. This variable was added to the survey later, causing 44 missing cases.

Control variables. Domain identification, that is, the extent to which participants identified with learning Dutch, was measured with six items (Smith \& White, 2001), which included, for example, "Dutch is one of my best topics." Responses were provided on scales of 1 (not at all) to 7 (very much) $(M=5.43$, $S D=1.01, \alpha=.78$ ). General trait test anxiety was measured with an eight-item version of the Dutch Test Anxiety scale (Spielberger, 1988), which included, for example, "I feel really nervous if I take an important exam" $(1=$ never, $7=$ always, $M=3.70, S D=1.48, \alpha=.91$ ).

\section{Results}

We estimated different regression models using MLR estimation ${ }^{3}$ with test performance, performance state self-esteem, and anxiety as outcome variables and with dual identity and the experimental manipulation of ST as predictors using Mplus 7.3 (Muthén \& Muthén, 1998-2012). ${ }^{4}$ We calculated simple slopes and tested the significance of mean differences via the Wald test in Mplus. Different mean comparisons indicate support for the predicted benefits and costs of dual identities in low versus high-threat contexts: (1) a positive effect of dual identity in the control condition so that dual identifiers do better than otherwise-identified students in the control (but not in the threat) condition; (2) a negative effect of ST among dual identifiers so that they do worse in the ST condition compared to the control condition, and (3) a negative effect of dual identity in the ST condition so that dual identifiers do worse than otherwise-identified students in the ST condition. Table 1 shows the results of the regression analyses.

Dual identity predicted higher performance, but this main effect was qualified by a two-way interaction between dual identity and condition $(p=.022)$. (1) The

\footnotetext{
${ }^{3}$ MLR (Maximum Likelihood Estimation with Robust Standard Errors) gives maximum likelihood parameter estimates with standard errors and a chi-square test statistic that are robust to non-normality.

${ }^{4}$ Looking at the correlations between performance, state self-esteem, and anxiety, objective performance was unrelated to self-report measures of affective responses. Thus, we did not perform mediational analyses.
} 
Table 1. Regression Models Predicting Performance, Anxiety, Dejection, and Self-Esteem

\begin{tabular}{lccc}
\hline & Test Performance & Anxiety & Self-Esteem \\
\hline Threat condition & $-.03(.22)$ & $.39(.24)$ & $-.05(.14)$ \\
Dual identity & $.15(.07)^{*}$ & $-.06(.10)$ & $.13(.05)^{*}$ \\
Threat*identity & $-.26(.12)^{*}$ & $.26(.16)^{\mathrm{a}}$ & $-.16(.08)^{\mathrm{b}}$ \\
Trait anxiety & $\mathrm{ns}$ & $\mathrm{ns}$ & $-.28(.05)^{* * *}$ \\
Domain Id & $\mathrm{ns}$ & $-.44(.13)^{* *}$ & $.35(.07)^{* * *}$ \\
Explained variance $\left(R^{2}\right)$ & .033 & .11 & .35 \\
\hline
\end{tabular}

Note: This table shows unstandardized regression coefficients and standard errors $(S E)$ in parentheses. NS indicates nonsignificant effects that were dropped from the analysis.

${ }^{*} p<.05 .{ }^{* *} p<.01 .{ }^{* * *} p<.001 .{ }^{\mathrm{a}} p=.096 .{ }^{\mathrm{b}} p=.061$.

positive relation between dual identity and performance was significant in the control condition, $t=2.05, p=.040$, while the negative relation between dual identity and performance in the ST condition was not significant, $t=-1.24, p>$ .100. Namely, dual identifiers did significantly better in the control condition than their otherwise-identified peers ( $M \mathrm{~s}=2.29$ vs. 1.78 , respectively); this advantage of dual identifiers disappeared in the threat condition $(M \mathrm{~s}=1.81$ vs. 2.19). (2) When comparing dual identifiers in the ST $(M=1.81)$ and control conditions $(M=2.29)$, the slope was not significant but it was in the expected direction, $t=$ $-1.69, p=.092$. Finally, (3) dual identifiers did not do significantly worse than otherwise-identified students in the ST condition.

Dual identity predicted higher self-esteem and this main effect was qualified by a trend-significant two-way interaction between dual identity and condition, $p=.061$. (1) The positive relation between dual identity and self-esteem was significant in the control condition, $t=2.39, p=.017$, while the negative relation between dual identity and self-esteem in the ST condition was not significant, $t=-.41, p>.100$. Thus, dual identifiers had higher self-esteem $(M=5.29)$ than otherwise-identified students $(M=4.85)$ in the control condition but this benefit disappeared in the ST condition $(M \mathrm{~s}=4.98$ vs. 5.07). Dual identifiers did not feel worse in the ST condition compared to (2) those in the control condition, $t=$ $-1.48, p>.10$, or to (3) otherwise-identified students, yielding no evidence of the predicted costs of dual identities in high-threat contexts.

For anxiety, although the two-way interaction between the condition and dual identity was not significant, $p=.096,{ }^{5}$ simple slopes suggested a similar trend. (1) Dual identifiers and otherwise-identified students felt similarly anxious in

\footnotetext{
${ }^{5}$ We conducted both univariate and multivariate outlier analyses and found one multivariate outlier with anxiety. With the inclusion of the outlier, the interaction becomes $B=0.22, S E=.16, p=.171$, while the Wald test still shows a significant difference for the dual identifiers in the threat and control conditions $(p=.018)$. Given the nonsignificant $p$ value and dependence on the outlier, we interpret the effect on anxiety with caution.
} 
the control condition $(M s=2.71$ vs. $2.92, p>.100)$, yielding no evidence of the predicted benefits of dual identities in low-threat contexts. However, a dual identity was revealed as a costly strategy in high-threat contexts, as predicted. (2) The effect of ST for dual identifiers was significant, $t=2.39, p=.017$ : Dual identifiers felt more anxious in the threat $(M=3.54)$ than in the control condition $(M=2.71)$. (3) The relation between dual identity and anxiety in the ST condition was in the expected direction, $t=1.68, p=.094$, so that dual identifiers felt slightly more anxious $(M=3.54)$ than did otherwise-identified students in the ST condition $(M=2.87)$.

\section{Discussion}

Study 1 aimed to examine the role of dual identities in their response to ST in a selective sample of high-achieving and academically oriented minority students. Our findings supported the predicted benefits of dual identities in low-threat contexts: Dual identifiers outperformed and had higher self-esteem than otherwiseidentified peers in the control condition. In line with our research hypothesis about the vulnerability of dual identifiers in the face of ST, however, this adaptive advantage of dual identifiers disappeared in the threat condition. Study 1 also had limitations. A high score on the direct measure of dual identity signifies the striving to combine both cultures and identities (Brown \& Zagefka, 2011), yet a low score might mean "separation" or "assimilation" or neither, so its meaning is less clear (Verkuyten et al., 2019). Moreover, focusing on academically oriented students, as in the original experiments (Steele et al., 2002), restricts the external validity of the study, because immigrant minority students in Europe are often over-represented in vocational schools (Baysu et al., 2018). Finally, the only evidence of the predicted costs of dual identities in high-threat contexts pertained to feelings of anxiety and the effects were marginal. Therefore, Study 2 aimed to replicate and extend the findings of Study 1, using large-scale academically heterogeneous samples, a different dual identity measure, a nonverbal test, and a double-blind assignment of schools to conditions controlling for compositional differences across schools.

\section{Study 2}

Study 2 aimed to replicate the role of dual identities in minority performance under ST in a large-scale field experiment with more representative academically heterogeneous samples of Turkish and Moroccan Belgian minority students. The experiment was embedded in a large-scale survey of Turkish and Moroccan minority students in 47 secondary schools in Belgium (CILS-Belgium). Schools were assigned to either experimental or control conditions, using a slightly different manipulation of ST from Study 1. In the ST condition, students answered ethnicity 
questions before taking a performance test, whereas in the control condition, they answered the same questions after the test. Such minimal ST manipulations (e.g., by asking demographic questions before or after a performance test) proved consequential for women's math scores in a real-life application (Danaher \& Crandall, 2008). Assignment of schools, rather than students, ensured that students and teachers were blind to the conditions. This study aimed to strengthen the ecological validity of Study 1 by covering a more representative academically heterogeneous population of minority students across different types of schools.

Study 2 assessed performance on an inductive reasoning test as a measure of nonverbal cognitive ability (Cattell \& Cattell, 1961). This test relies less on Dutch language mastery, and is thus more suited to an academically heterogeneous sample of minority students, including many students with restricted Dutch literacy. Our choice of a nonverbal test is in line with a meta-analysis of ST studies with immigrant populations showing stronger ST effects on nonverbal cognitive performance tests than on verbal tests (Appel et al., 2015). ${ }^{6}$

We measured dual identity indirectly as the statistical interaction of minority culture maintenance and majority culture adoption in the school domain (Baysu et al., 2011). We contextualized the cultures in the school domain because we were interested in academic outcomes and because dual identities are most preferred in the public domain (Arends-Toth \& Van De Vijver, 2003). In line with a well-established bi-dimensional approach of acculturation and identity (Berry et al., 2006), we distinguished a dual identity (investing in both minority- and majority-cultures in school) from alternate separated (investing mainly in the minority culture) or assimilated identities (investing mainly in the majority culture). A residual category (investing in neither culture) was labeled "marginalized identity."

\section{Method}

Participants. All students in 47 randomly selected secondary schools in Belgium participated in the field experiment during class hours. Participants were Turkish and Moroccan Belgian minority students $(N=735$, boys 59\%), most of whom were second-generation $(81 \%)$ (local-born with one or both parents born abroad), with fewer first (15\%) and third-generation students (4\%). Students were in their first (31\%), second (34\%), or third year (35\%) of lower secondary school

\footnotetext{
${ }^{6}$ The study included a test of verbal ability using a shortened form of Dutch synonym test. Because the sample in Study 2 was very heterogeneous with half of the minority students from vocational (so-called low-achieving) schools, we did not expect any situational threat effects on this test. However, we found a trend in support of the predicted costs of dual identity in high-threat contexts (See Supplementary Online Material) at https://mfr.osf.io/render?url=https\%3A\%2F\%2Fosf. io $\% 2$ Furbkq $\% 2$ Fdownload.
} 
and their ages ranged from 12 to 18 years $(M=14.5 ; S D=1.3)$ (excluding the two age outliers, 19 and 22 years, $z>3){ }^{7}$ Most minority students attended vocational schools with smaller portions in selective professional (16\%) or academic schools $(32 \%)$.

Procedure and Design. The experiment was embedded in the CILSBelgium survey with a school-based stratified random sampling design (for codebook, Phalet, Meuleman, Hillekens, \& Sekaran, 2019). The research was introduced as part of the international "Youth in Europe Study" about the daily life of European youth. The 47 schools were randomly assigned to either the ST (272 minority students in $n=23$ schools) or the control condition ( $n=425$ minority students in $n=24$ schools). In the control condition, students took the tests directly upon arrival in class. After the test, they were given a questionnaire with ethnicity questions (such as language spoken at home, religious practice, their parents/grandparents' country of birth). In the threat condition, students first filled out the ethnicity questions. To de-emphasize the evaluative nature of the tests in both conditions, as in the original experiments (Steel \& Aronson, 1995), general instructions ensured that their responses would be anonymous; and the stated purpose of the research was to investigate cognitive strategies used to solve some puzzles. The only difference between experimental and control conditions was the order of the test and the ethnicity questions. Students had 7 minutes to complete the inductive reasoning test.

Measures. Nonverbal test performance was measured as the average score of 27 items from the inductive reasoning subtest of the Culture Fair Intelligence Test (Cattell \& Cattell, 1961), $M=0.59, S D=0.21$.

Dual identity was measured as the product of two dimensions of acculturation in the school domain (Arends-Toth \& Van De Vijver, 2003): "Think about the country where your parents or grandparents were born. How important is it for you to maintain the customs of this country in school?" (minority culture maintenance, $M=2.59, S D=0.96$ ); "Now think about Belgium. How important is it for you to adopt the Belgian customs at your school?" (culture adoption, $M=2.81$, $S D=0.87)$. Answers were given on 5-point scales $(1=$ not important at all, $5=$ very important). The two dimensions were positively correlated, $r=.21$, $p<.001$.

Control variables were included to account for compositional differences across schools. Grade retention $(1=$ retained, $0=$ not retained $)$, year of education (1st, 2nd vs. 3rd years), and school track (vocational, professional vs. academic

\footnotetext{
${ }^{7}$ Results were robust with or without age outliers.
} 
tracks) were measured with dummy-coded variables. School ethnic composition, age, and gender were dropped from the analyses since they were not significant.

\section{Results}

We ran multilevel models with MLR estimation using Mplus 7.3 (Muthén \& Muthén, 1998-2012), with experimental condition, dual identities, and their interactions as predictors and performance as outcome measure. We first estimated a null model with a random intercept only. The residual variance in performance levels was significant both at the individual and the school levels (Table 2). Moreover, the intra-class correlation $(I C C=.114)$, defined as the proportion of the total variance found at the school level, supported the adoption of a multilevel approach.

We compared models using the Satorra-Bentler scaled chi-square difference test, Akaike's Information Criterion (AIC), and Bayesian Information Criterion (BIC) (smaller values of AIC or BIC indicate better fit). The following variables were entered in each step: control variables ("Model Control" in Table 1), the experimental condition ("Model Threat"), acculturation measures of dual identity ("Model Acculturation"), random slopes of culture maintenance, adoption, and their interaction ("Model 3 Slopes"), and the cross-level interactions between threat, culture adoption, and maintenance ("Full Model"). Each subsequent model significantly improved the model fit over the previous model. Of all random slopes, only the interaction of maintenance and adoption varied significantly between schools.

As expected, the three-way interaction was significant, $p=.035$. Looking at simple slopes (Figure 1), (1) dual identifiers did not outperform others in the control condition, all $p s>.100$, thus yielding no evidence of the predicted benefits of dual identity in low-threat contexts. However, in support of the predicted costs of dual identities in high-threat contexts, (2) the effect of ST was significant among dual identifiers, $t=-2.21, p=.027$; they did significantly worse in the ST than in the control condition. No other slope was significant (assimilated $t=0.39$, separated $t=0.71$, marginalized $t=-1.01$, all $p \mathrm{~s}>.100$ ). Moreover, (3) dual identifiers did significantly worse in the ST condition than did all otherwise identified students (separated, $p=.013$; assimilated $p=.002$; marginalized, $p<.001)$

\section{Discussion}

The findings of Study 2 lend support to hypothesized downsides of dual identities in threatening performance contexts. In line with our hypothesis about the vulnerability of dual identifiers in the face of ST, they indeed performed worse in the threat condition, compared to the control condition and compared to 


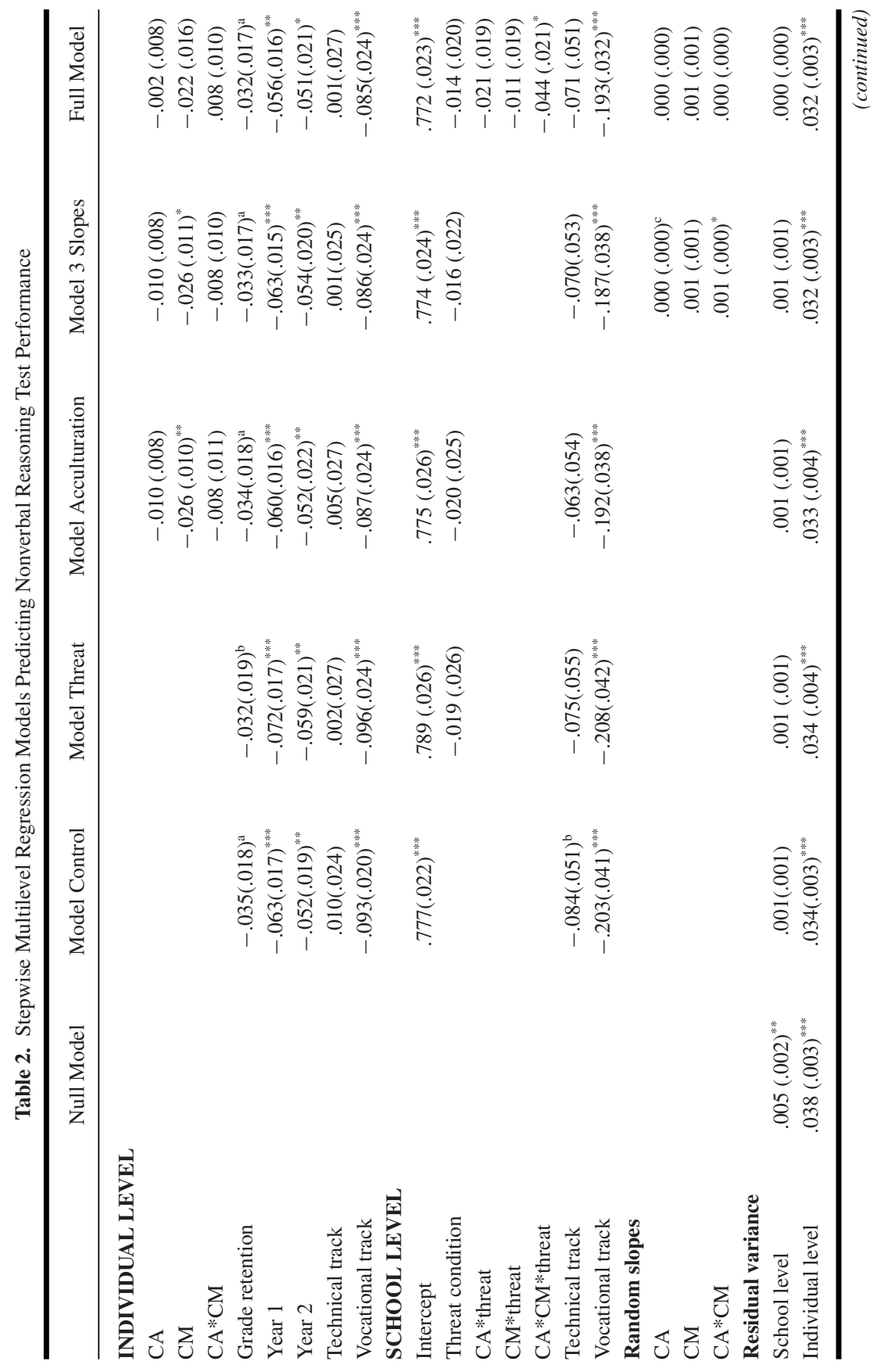




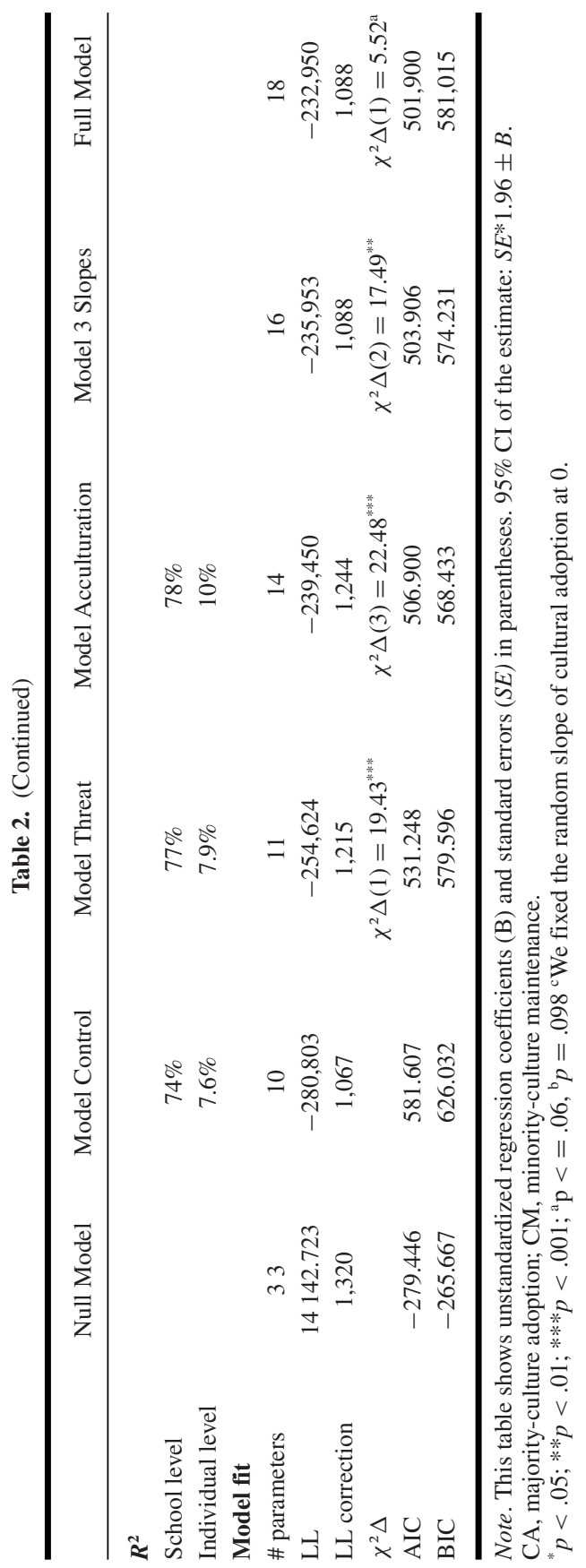




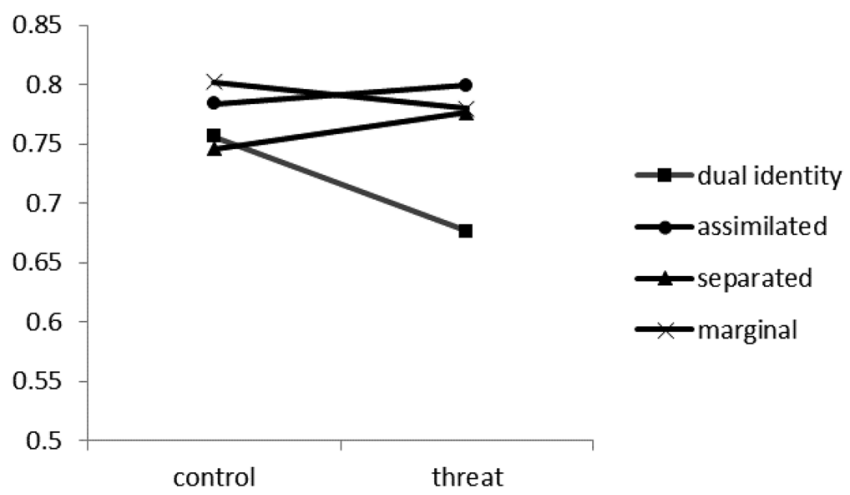

Fig. 1. Effects of stereotype threat on the performance of students with different acculturationorientations on a nonverbal cognitive test.

those with other identifications in the threat condition. Unlike Study 1, however, Study 2 found no support for the predicted benefits of dual identity in low-threat contexts.

Study 2 is one of the few field-experiments inducing ST in large randomsamples of immigrant minority students in European academic contexts (Baysu et al., 2016). Because the experiment was embedded in a large-scale school-based survey, the ST manipulation was minimal, with school-level random-assignment to conditions, and our measure of dual identity was equally restricted. On the positive side, the embedded experimental design allowed us to include large numbers of academically disadvantaged minority students in vocational secondary schools. Thus, we were able to establish the ecological validity of ST processes beyond the usual highly selective academic environments (cf. Study 1). The current study also goes beyond our previous study, which documented the main effect of ST using the same data set (Baysu et al., 2016) by showing the interplay of ST with dual identity.

\section{General Discussion}

Summing up, both field experiments aimed to examine the interaction of dual identity with ST in the academic performance of minority students. In line with our research hypothesis, dual identifiers were most vulnerable to experimentally induced ST. Accordingly, dual identifiers outperformed, and had higher selfesteem, than otherwise-identified students in the control condition, while this advantage of dual identity disappeared in the threat condition (Study 1). Dual identifiers also reported more anxiety (Study 1) and performed worse (Study 2) in the threat condition than in the control condition. 


\section{Stereotype Threat}

Our findings provide consistent evidence for ST as a general mechanism underlying academic underperformance in minority students across two field experiments with slightly different manipulations, different dual identity measures, and different minority samples. Thus, we contribute to still limited yet growing evidence of ST in immigrant minorities in Europe (Baysu et al., 2016, using the same data set; Froehlich, Mok, Martiny, \& Deaux, 2018, for Turkish minorities in Germany). Moreover, while recent research on ST addressed the role of minority identities in coping with threat, the question of which identity strategies might mitigate or exacerbate threat effects on minority performance has not yet been answered. Indeed, a meta-analysis of ST studies with immigrant populations (Appel et al., 2015) reports inconsistent findings of negative, zero, or positive moderation of ST effects by ethnic identity. Our research suggests a way forward by addressing the neglected role of dual identities. Since dual identifiers are identified with both the target (the minority group) and the source of threat (majority group; Shapiro et al., 2013; Shapiro \& Neuberg, 2007), we expected and found that they are most vulnerable to ST.

\section{Identity Multiplicity: Social Identity and Acculturation}

Our research also contributes to a social identity approach of identity multiplicity in acculturation research. First, the findings confirm possible upsides and downsides of dual identities for minorities' psychological adjustment and achievement (Baysu et al., 2011; Brown et al., 2013; Makarova \& Birman, 2015). From a social identity performance perspective (Klein et al., 2007), dual identifiers are responsive to the double valuation of their identities by both minority and majority group members, which also makes them most susceptible to cues of devaluation in their environment. Although acculturation studies find that an adaptive advantage of dual identities varies considerably across intergroup contexts, the processes underlying these contingencies have not yet been systematically theorized or tested (Berry et al., 2006). Our research provides novel multilevel and experimental evidence of these contingencies (Baysu et al., 2011; Celeste et al., 2016) and advances identity threat as a process that can account for contextual constraints on the adaptive value of dual identities. We conclude that dual identities can be psychologically beneficial or costly for minorities depending on the presence or absence of identity threat in the intergroup context.

Moreover, we find evidence of the contingent benefits and costs of dual identities, in line with mixed evidence of an adaptive advantage (Berry et al. 2006; Brown et al., 2013; Makarova \& Birman, 2015; Nguyen \& Benet-Martínez, 2013) as well as possible disadvantages in the acculturation literature (Baysu et al., 2011; Brown et al., 2013). Still, we did not find consistent benefits of dual identities in 
the academic context across the two studies. One reason could be chronically high levels of identity threat for Muslim minorities in today's schools. It is possible that chronic identity threats, such as discriminatory treatment and negative stereotyping, are even higher for our low-achieving minority students in vocational schools in Study 2. Against this background, our control condition likely fell short of lifting threat, so that our findings may underestimate the benefits of dual identity in the absence of ST. In support of this reasoning, earlier research yielded correlational evidence showing that dual identifiers who reported no discrimination in school significantly outperformed their minority peers with other identity strategies (Baysu et al., 2011).

An additional strength of our research is that we replicated the interplay of ST with the dual identities of minorities using two distinct measures of dual identity. We defined dual identity as minorities' self-investment in combined minority and majority cultures and identities, and as distinct from deeper psychological aspects of identity (Verkuyten et al., 2019). We used acculturation measures of "integration" to assess dual identity in terms of the endorsement of both minority and majority cultures in school. The statistical interaction of both components is an indirect way to identify the unique effect of dual identity. Combining measures that refer to each cultural identity separately is a common way of operationalizing dual identification (Baysu et al., 2011; Brown \& Zagefka, 2011). This method was criticized, however, as less suited to capture the psychological experience of compatibility between minority and majority cultures (Benet-Martínez \& Haritatos, 2005). Therefore, we also used an additional direct measure of dual identity, which captures the psychological experience of feeling part of a combined culture and identity (Benet-Martínez \& Haritatos, 2005). We reasoned that dual identitieshowever, measured-could be psychologically costly for minority performance in the face of threat. Accordingly, using a different measure of dual identification (as dual commitments to ethnic and national identities), our own previous findings associated dual identities with lower school attainment in the face of high discrimination as a chronic source of identity threat (Baysu et al., 2011).

Another strength of our research is its experimental design and the use of test performance as an outcome measure. As most acculturation research is limited by over-reliance on correlational evidence and by a restrictive focus on well-being or attitudinal outcomes (Brown \& Zagefka, 2011; Phalet \& Baysu, 2019), we thus provide more stringent evidence of the real consequences of an "integration" strategy of acculturation.

Finally, we did not find significant effects of ST for alternate separated (stressing the minority culture and identity) or assimilated identities (stressing the majority culture and identity) in Study 2. Plausibly, separated identifiers are less vulnerable to threat because they attach less value to the majority group as source of threat. Conversely, assimilated identifiers may be protected from threat because they attach less value to the minority group as target of threat. Similarly, 
ST research on multiply-held identities reveals that shifting focus away from the stereotyped minority identity to a nonstereotyped group identity, a majority identity in this case, attenuates threat effects (McGlone \& Aronson, 2006), or may even enable a challenge response, that is, increased performance in the face of threat (Weber, Appel, \& Kronberger, 2015).

\section{Limitations}

Our studies had several limitations. Randomly assigning schools rather than students to conditions may have confounded experimental effects with other school characteristics, even though we controlled statistically for compositional differences across schools. There is a trade-off between maximizing external or internal validity so that internal validity is weaker in Study 2, due to school-level assignment to conditions in a large-scale field study, and stronger in Study 1, with individual-level assignment to conditions in smaller yet more restricted minority samples. An additional methodological limitation is our use of single indicators and a two-item composite to assess dual identities. Although the hypothesized interaction with ST is robust across different measures (including the more stable identity dimension, see also Baysu et al., 2011), more fine-grained composite measures of dual identities would be required to examine whether the findings generalize to other dimensions of dual identity.

\section{Policy Implications}

In spite of its limitations, our research findings have wider applied implications. As identity multiplicity is the rule among minority youth, spelling out the interplay of identity threat with dual identities is key to advance our understanding of persistent minority-majority performance gaps. While an environment where dual identity claims are questioned or rejected may undercut a potential psychological advantage of dual identifiers, such an environment may be less threatening for assimilated identifiers. There is a caveat, however, because assimilationist pressures may backfire, so there is no easy way to shift focus away from the stereotyped minority identity to the (nonstereotyped) national majority culture and identity. Indeed, a separate line of research on the common in-group identity model suggests that highlighting a superordinate identity without acknowledging minorities' distinct subgroup identities increases threat perceptions (Dovidio, Gaertner, \& Saguy, 2007). Alternatively, our findings suggest double valuation of both minority and majority cultures and identities as a most promising way to protect dual identifiers from the downstream consequences of identity threat.

Moreover, as ST is generally less researched in the European migration context, our research supports the ecological validity and the applied relevance of 
mostly U.S.-based ST research for immigrant minorities in Europe. The wider societal intergroup context is crucial for an accurate understanding of the real consequences of dual identities for different ethnic minorities (Berry et al., 2006). In Europe, dual identities, such as Moroccan-Belgian or Turkish-Belgian, are less supported by public opinion and hence psychologically less viable than in the United States, where hyphenated identities, such as Mexican-American or AsianAmerican, are more commonly claimed and recognized (Verkuyten et al., 2019; Verkuyten \& Martinovic, 2012). Moreover, in Europe, majorities commonly perceive minority cultures and identities as incompatible with the national majority culture and identity (Verkuyten \& Martinovic, 2012). Against this background, a dual identity entails a heightened sensitivity to situational cues of devaluation of one's minority culture and identity by the majority group.

Importantly, our findings most likely underestimate realistic threat levels for Muslim minorities in academic settings because the testing environment in our studies (anonymized, not diagnostic, no consequences) is a safer version of the daily reality of high-stakes testing. While we took care to de-emphasize the evaluative nature of the tests in our studies, in real-life academic settings threat is in the air; and stigmatized minority students in particular are sensitive to situational cues signaling identity threat. In these settings, test scores have important real-life consequences for future chances. Paradoxically, our findings imply that ST may put those minority students who are well integrated in both minority and majority cultures at a disproportionate risk.

To conclude, our studies with stigmatized Muslim minorities in a European migration and educational context showed that dual identity is a two-edged sword. It can boost minority success in the absence of ST, yet it can also undermine success in the presence of threat. Taking into account the interplay of dual identities with ST should allow a more balanced view of the psychological benefits and costs of promoting dual identities for minority outcomes. In particular, the findings draw attention to the vulnerability of dual identifiers when they face identity threat in less supportive intergroup settings. At the same time, they are suggestive of a potential advantage of dual identifiers when their cultural identities and engagements are valued in the eyes of powerful majority groups and institutions.

\section{References}

Ambady, N., Shih, M., Kim, A., \& Pittinsky, T. L. (2001). Stereotype susceptibility in children: Effects of identity activation on quantitative performance. Psychological Science, 12, 385-390.

Appel, M., Weber, S., \& Kronberger, N. (2015). The influence of stereotype threat on immigrants: A meta-analytic review. Frontiers in Psychology, 6, 900.

Arends-Tóth, J., \& Van De Vijver, F. J. R. (2003). Multiculturalism and acculturation: Views of Dutch and Turkish-Dutch. European Journal of Social Psychology, 33, 249-266. 
Aronson, J., \& Inzlicht, M. (2004). The ups and downs of attributional ambiguity: Stereotype vulnerability and the academic self-knowledge of African American college students. Psychological Science, 15, 829-836.

Ashmore, R. D., Deaux, K., \& Mclaughlin-Volpe, T. (2004). An organizing framework for collective identity: Articulation and significance of multidimensionality. Psychological Bulletin, 130, 80-114.

Badea, C., Jetten, J., Iyer, A., \& Er-Rafiy, A. (2011). Negotiating dual identities: The impact of groupbased rejection on identification and acculturation. European Journal of Social Psychology, $41,586-595$.

Baysu, G., Celeste, L., Brown, R., Verschueren, K., \& Phalet, K. (2016). Minority adolescents in ethnically diverse schools: Perceptions of equal treatment buffer threat effects. Child Development, $87,1352-1366$

Baysu, G., de Valk, H., \& Alanya, A. (2018). School trajectories of the second-generation of Turkish immigrants in Sweden, Belgium, Netherlands, Austria and Germany: The role of school systems. International Journal of Comparative Sociology, 59, 451-479.

Baysu, G., Phalet, K., \& Brown, R. (2011). 'Dual' identity as a two edged sword: Identity threat and minority school performance. Social Psychology Quarterly, 74, 121-143.

Benet-Martínez, V., \& Haritatos, J. (2005). Bicultural identity integration (BII): Components and psychosocial antecedents. Journal of Personality, 73, 1015-1050.

Berry, J. W., Phinney, S. P., Sam, D. L., \& Vedder, P. (Eds.). (2006). Immigrant youth in cultural transition. Acculturation, identity and adaptation across national contexts. Mahwah, NJ: Lawrence Erlbaum.

Branscombe, N., Ellemers, N., Spears, R., \& Doosje, B. (1999). The context and content of social identity threat. In N. Ellemers, R. Spears, \& B. Doosje (Eds.), Social identity, context, commitment, content (pp. 35-58). Oxford, UK: Blackwell.

Brown, R., Baysu, G., Nigbur, D., Rutland, A., Watters, C., Cameron, L., ... Landau, A. (2013). Acculturation attitudes and social adjustment in ethnic minority British children: A longitudinal study. Personality and Social Psychology Bulletin, 39, 1656-1667.

Brown, R., \& Zagefka, H. (2011). The dynamics of acculturation: An intergroup perspective. Advances in Experimental Social Psychology, 44, 129-184.

Cardenas, D. (2019). Dual identity, minority group pressure and the endorsement of minority rights: A study among Sunni and Alevi Muslim in Western Europe. Journal of Social Issues, This Issue.

Cattell, R. B., \& Cattell, A. K. S. (1961). Test of " $g$ ": Culture fair. Champaign, IL: Institute for Personality Ability Testing.

Celeste, L., Meeussen, L., Verschueren, K., \& Phalet, K. (2016). Minority acculturation and peer rejection: Costs of acculturation misfit with peer-group norms. British Journal of Social Psychology, $55,544-563$.

Crisp, R. J., \& Turner, R. N. (2011). Cognitive adaptation to the experience of social and cultural diversity. Psychological Bulletin, 137, 242-266.

Danaher, K., \& Crandall, C. S. (2008). Stereotype threat in applied settings re-examined. Journal of Applied Social Psychology, 38, 1639-1655.

Deaux, K., Bikman, N., Gilkes, A., Ventuneac, A., Joseph, Y., Payne, Y., \& Steele, C. (2007). Becoming Americans: Stereotype threat effects in Afro-Caribbean immigrant groups. Social Psychology Quarterly, 70, 384-404.

Derks, B., van Laar, C., \& Ellemers, N. (2007). The beneficial effects of social identity protection on the performance motivation of members of devalued groups. Social Issues and Policy Review, $1,217-256$.

Dovidio, J. F., Gaertner, S. L., \& Saguy, T. (2007). Another view of “we”': Majority and minority group perspectives on a common ingroup identity. European Review of Social Psychology, 18, 296-330.

Ellemers, N., Spears, R., \& Doosje, B. (2002). Self and social identity. Annual Review of Psychology, 53, 161-186.

Froehlich, L., Mok, S. Y., Martiny, S. E., \& Deaux, K. (2018). Stereotype threat-effects for Turkishorigin migrants in Germany: Taking stock of cumulative research evidence. European Educational Research Journal. http://doi.org/10.1177/1474904118807539 
Heath, A., \& Brinbaum, Y. (2014). Unequal attainments. Oxford, UK: Oxford University Press.

Heatherton, T. F., \& Polivy, J. (1991). Development and validation of a scale for measuring state self-esteem. Journal of Personality and Social Psychology, 60, 895-910.

Klein, O., Spears, R., \& Reicher, S. (2007). Social identity performance: Extending the strategic side of SIDE. Personality and Social Psychology Review, 11, 28-45.

Luteijn, F., \& van der Ploeg, F. A. E. (1983). Groninger intelligentie test (GIT). Swets \& Zeitlinger.

Makarova, E., \& Birman, D. (2015). Cultural transition and academic achievement of students from ethnic minority backgrounds: A content analysis of empirical research on acculturation. Educational Research, 57, 305-330.

McGlone, M. S., \& Aronson, J. (2006). Stereotype threat, identity salience, and spatial reasoning. Journal of Applied Developmental Psychology, 27, 486-493.

Mok, A., Morris, M., Benet-Martínez, V., \& Karakitapoglu-Aygun, Z. (2007). Embracing American culture: Structures of social identity and social networks among first-generation biculturals. Journal of Cross-Cultural Psychology, 38, 629-635.

Muthén, B., \& Muthén, L. (1998-2012). Mplus. Los Angeles, CA: Muthén \& Muthén. [Computer software].

Nguyen, A. M., \& Benet-Martínez, V. (2013). Biculturalism and adjustment: A meta-analysis. Journal of Cross-Cultural Psychology, 44, 122-159.

OECD. (2015). Immigrant students at school: Easing the journals towards integration. Paris: OECD.

Phalet, K., \& Baysu, G. (2019). Fitting in: How the intergroup context shapes minority acculturation and achievement. European Review of Social Psychology. Accepted for Publication.

Phalet, K., Baysu, G., \& Verkuyten, M. (2010). Political mobilization of Dutch Muslims: Religious identity salience, goal framing, and normative constraints. Journal of Social Issues, 66, 759779.

Phalet, K., Fleischmann, F., \& Hillekens, J. (2018). Religious identity and acculturation of minority youth: Towards a contextual and developmental approach. European Psychologist, 23, 32-43.

Phalet, K., Meuleman, B., Hillekens, J., \& Sekaran, S. (2019). CILS technical report longitudinal 2012-2015. Leuven.

Ployhart, R. E., Ziegert, J. C., \& McFarland, L. A. (2003). Understanding racial differences on cognitive ability tests in selection contexts: An integration of stereotype threat and applicant reactions research. Human Performance, 16, 231-259.

Schmader, T. (2002). Gender identification moderates stereotype threat effects on women's math performance. Journal of Experimental Social Psychology, 38, 194-201.

Shapiro, J. R., \& Neuberg, S. L. (2007). From stereotype threat to stereotype threats: Implications of a multi-threat framework for causes, moderators, mediators, consequences, and interventions. Personality and Social Psychology Review, 11, 107-130.

Shapiro, J. R., Williams, A. M., \& Hambarchyan, M. (2013). Are all interventions created equal? A multi-threat approach to tailoring stereotype threat interventions. Journal of Personality and Social Psychology, 104, 277-288.

Smith, J. L., \& White, P. H. (2001). Development of the domain identification measure: A tool for investigating stereotype. Educational and Psychological Measurement, 61, 1040-1057.

Spencer, S. J., Steele, C. M., \& Quinn, D. M. (1999). Stereotype threat and women's math performance. Journal of Experimental Social Psychology, 35, 4-28.

Spielberger, C. D. (1988). Manual for the State-Trait Anger Expression Inventory (STAXI). Odessa, FL: Psychological Assessment Resources.

Steele, C. M., \& Aronson, J. (1995). Stereotype threat and the intellectual test performance of AfricanAmericans. Journal of Personality and Social Psychology, 69, 797-811.

Steele, C. M., Spencer, S. J., \& Aronson, J. (2002). Contending with images of one's group: The psychology of stereotype and social identity threat. In M. Zanna (Ed.), Advances in experimental social psychology (pp. 379-440). San Diego, CA: Academic Press.

Verkuyten, M., \& Kinket, B. (1999). The relative importance of ethnicity: Ethnic categorization among older children. International Journal of Psychology, 34, 107-118.

Verkuyten, M., \& Martinovic, B. (2012). Immigrants' national identification: Meanings, determinants, and consequences. Social Issues and Policy Review, 6, 82-112. 
Verkuyten, M., Wiley, S., Deaux, K., \& Fleischmann, F. (2019). To be both (and more): Immigration and identity multiplicity. Journal of Social Issues, This Issue.

Weber, S., Appel, M., \& Kronberger, N. (2015). Stereotype threat and the cognitive performance of adolescent immigrants: The role of cultural identity strength. Contemporary Educational Psychology, 42, 71-81.

Wiley, S., Fleischmann, F., Deaux, K., \& Verkuyten, M. (2019). Why immigrants' multiple identities matter: Implications for research, policy, and practice. Journal of Social Issues, This Issue.

GÜLSELI BAYSU is a Lecturer in the School of Psychology at Queen's University Belfast, UK. Her research interests focus on social psychology of cultural diversity, immigration and integration, educational success of immigrants and minorities, intergroup relations, identity processes, and political participation of minorities. In 2018, she received a grant from Jacobs Foundation for the project "Cultural diversity approaches in schools and their implications for student achievement and adjustment." She was also awarded with Advanced Research Center Distinguished Visiting Fellowship of City University of New York, where she worked for 6 months as a Visiting Professor.

KAREN PHALET is full professor at the Center for Social and Cultural Psychology of the University of Leuven (Belgium). She obtained her PhD in cultural psychology from the University of Leuven and she was previously associate professor at the Universities of Utrecht and Nijmegen, the Netherlands. Her research articulates a social and cultural psychology approach of the interplay between cultural diversity and social inequality in European societies. She has been involved in several major cross-national surveys of ethnic minorities across Europe. Her comparative research combines minority and majority group perspectives on intercultural relations - and their consequences for the acculturation, attainment, and inclusion. Recent publications examine a religious dimension of minority acculturation and inclusion/exclusion across different societal contexts, as well as acculturation ideologies and minority experiences of (mis)fit in intercultural interactions and relations. 